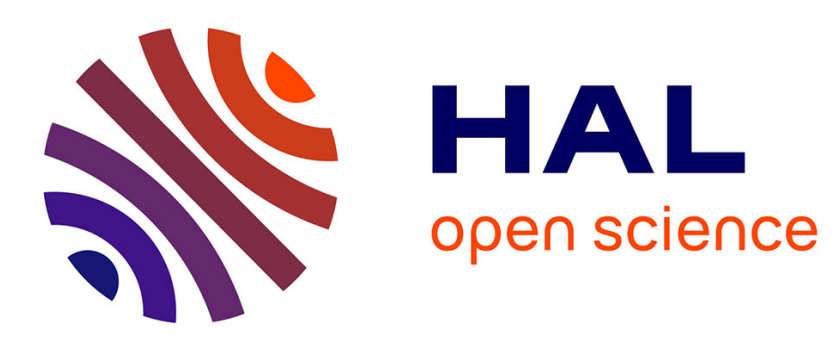

\title{
9,9 '-Spirobifluorene based zinc coordination polymers: a study on linker geometry and topology
}

Florian Moreau, Nathalie Audebrand, Cyril Poriel

\section{To cite this version:}

Florian Moreau, Nathalie Audebrand, Cyril Poriel. 9,9 '-Spirobifluorene based zinc coordination polymers: a study on linker geometry and topology. CrystEngComm, 2020, 22 (2), pp.293-303. 10.1039/c9ce01567a . hal-02470145

HAL Id: hal-02470145

\section{https://hal-univ-rennes1.archives-ouvertes.fr/hal-02470145}

Submitted on 10 Nov 2020

HAL is a multi-disciplinary open access archive for the deposit and dissemination of scientific research documents, whether they are published or not. The documents may come from teaching and research institutions in France or abroad, or from public or private research centers.
L'archive ouverte pluridisciplinaire HAL, est destinée au dépôt et à la diffusion de documents scientifiques de niveau recherche, publiés ou non, émanant des établissements d'enseignement et de recherche français ou étrangers, des laboratoires publics ou privés. 
9,9'-spirobifluorene based zinc coordination polymers: a play on linker geometry and topology

\title{
Florian Moreau $^{\mathrm{a}, \#}$, Nathalie Audebrand ${ }^{\mathrm{a} *}$, Cyril Poriel $^{\mathrm{a} *}$
}

${ }^{a}$ Univ Rennes, ENSCR, INSA, CNRS, ISCR (Institut des Sciences Chimiques de Rennes) UMR 6226, F-35000 Rennes, France

\# Now at Institut des Matériaux Poreux de Paris, FRE 2000 CNRS, Ecole Normale Supérieure, Ecole Supérieure de Physique et de Chimie Industrielles de Paris, Paris Research University, 75005 Paris, France

\begin{abstract}
We report four Zn-based coordination polymers (CPs), synthesized from three spirobifluorene (SBF) tetracarboxylate ligands, possessing different topologies and dimensionalities. Zn-SBF1, Zn-SBF-2 and Zn-SBF-3 CPs have 2D crystal structures with sql topology built from square planar ligands (L1 and L3) and paddle-wheels for Zn-SBF-1 or original dimers of zinc for Zn-SBF-2 and Zn-SBF-3. Zn-SBF-4 is built from a ligand with a distorted tetrahedron geometry (L2) and inorganic octahedral building unit resulting in a non-interpenetrated 3D porous framework with toc topology. Structural relationships evidence that meta (L2) versus para (L1, L3) position of the carboxylic functions on the benzoate group of the SBF ligand increases the connectivity of the inorganic building unit and then the dimensionality of the framework.
\end{abstract}

\section{Introduction}

Metal-Organic Frameworks (MOFs) or Porous Coordination Polymers (PCPs) have emerged as an important class of materials over the past twenty years, at first due to their fascinating crystal structures, mainly because they allow the control of porosity and its combination with various other properties making them suitable for a variety of applications such as gas storage and separation, heterogeneous catalysis, sensing, drug delivery and more recently as electronic or protonic conductors, valence tautomerism systems and for mixed matrix membranes. ${ }^{1}$ These coordination polymers (CPs) are built from inorganic secondary building units (SBU) and bridging organic linkers. Polycarboxylate linkers are most commonly used 
due to their ability to form suitable inorganic SBUs and to promote high dimensionality of the resulting frameworks. In this context we have been interested in the topology of PCPs and in the design and synthesis of ligands, in particular those based on the spirobifluorene (SBF) core. SBF is constituted of two orthogonal fluorene units connected through a shared spiro carbon. Thanks to this particular 3D geometry, SBF fragment has played a key role in the development of emerging technologies of organic electronics as it is a commonly used building unit in functional materials. ${ }^{2}$ The very specific geometry of the SBF scaffold has also allowed its use in many other applications such as fluorescent marker for biomolecules, ${ }^{3}$ homogeneous ${ }^{4}$ or heterogeneous ${ }^{5}$ catalysis of various chemical reactions (epoxidation, sulfoxidation...). Attaching anchoring functions to the backbone of the SBF fragment hence appears as an interesting strategy to construct 3D PCP with shape persistent structures. However, only ten coordination polymers built from SBF-based di- or tetracarboxylate ligands have been reported to date, ${ }^{6,7,8,9,10,11,12,13,14,15}$ six of them showing potential or permanent porosity. ${ }^{8-11,13,15}$ In the course of our study on SBF-based CPs, we reported a $\mathrm{Cu}^{\mathrm{II}}$ based compound with a tetrabenzoïc SBF ligand designed for that aim. ${ }^{15}$ Inorganic SBUs are often formed in situ without any real rationalisation, which limits the topological prediction of the PCP, whereas the organic building units stay robust during the assembly procedure. In this context, and in order to tune the topologies and then the porosity of the resulting PCP, we have designed in this work differently substituted SBF-based tetracarboxylic ligands with their anchoring functions localized at different positions of the molecular fragment. Four $\mathrm{Zn}$ based CPs with different topologies and dimensionalities were successfully obtained. The structural relationships between these CPs are discussed. It is evidenced that the association of square planar ligands of different sizes with inorganic SBUs like paddle-wheels or dimers leads to $2 \mathrm{D}$ structures with the $s q l$ topology. For two of the reported 2D structures, the layers are built from original distorted paddle-wheel zinc dimers and the stacking of the layers depends on the molecule occupying the apical position of the zinc polyhedra governing the weak interactions between the layers. On the other hand, switching from para- to metabenzoate units generates different inorganic SBUs with higher connectivity and allows the formation of a framework with higher dimensionality, in that case, a non-interpenetrated 3D PCP with a toc underlying net topology. The structural relationships between the four new CPs and related SBF-based CPs reported in the literature highlights the predominant role of the ligand geometry on the topology of the resulting coordination polymers.

\section{Experimental}




\section{General techniques, materials and methods}

Commercially available reagents and solvents were used without further purification other than those detailed below. Light petroleum refers to the fraction with b.p. $40-60{ }^{\circ} \mathrm{C}$. Dichloromethane was distilled from $\mathrm{P}_{2} \mathrm{O}_{5}$ drying agent Sicapent (Merck). Semiconductor grade toluene has been used. Reactions were magnetically stirred. Analytical thin layer chromatography was carried out using aluminium backed plates coated with Merck Kieselgel 60 GF254 and visualized under UV light (at 254 and/or $365 \mathrm{~nm}$ ). Chromatography was carried out using silica 60A CC 40-63 mm (SDS). ${ }^{1} \mathrm{H}$ and ${ }^{13} \mathrm{C}$ NMR spectra were recorded using Bruker $300 \mathrm{MHz}$ instrument $\left({ }^{1} \mathrm{H}\right.$ frequency, corresponding ${ }^{13} \mathrm{C}$ frequency is $75 \mathrm{MHz}$ ); chemical shifts were recorded in ppm and $J$ values in Hz. The residual signals for the NMR solvents are: $\mathrm{CDCl}_{3}, 7.26 \mathrm{ppm}$ for the proton and $77.00 \mathrm{ppm}$ for the carbon; [D6]DMSO, 2.50 ppm for the proton and $39.52 \mathrm{ppm}$ for the carbon. The following abbreviations have been used for the NMR assignment: $\mathrm{s}$ for singlet, $\mathrm{d}$ for doublet, sd for doubled singlet, $\mathrm{t}$ for triplet, $\mathrm{m}$ for multiplet and br for broad.

High-resolution mass spectra were recorded at the Centre Regional de Mesures Physiques de l'Ouest (Rennes) on a Bruker MicrO-Tof-Q2 and reported as m/z. Names of chemicals have been determined according to systematic nomenclature rules agreed upon by the International Union of Pure and Applied Chemistry.

\section{Synthesis}

\section{Syntheses of ligands $\mathrm{H}_{4} \mathrm{~L} 1, \mathrm{H}_{4} \mathrm{~L} 2$ and $\mathrm{H}_{4} \mathrm{~L} 3$.}

2,2',7'7'-tetrabromo-9,9' '-spirobifluorene (1) and 4,4',4', ,4',' -(9,9'spirobifluorene-2,2', 7,7'tetrayl)tetrabenzoic acid $\left(\mathbf{H}_{\mathbf{4}} \mathbf{L 1}\right)$ were synthesized as previously described ${ }^{15}$.

\section{3,3',3', 3' ',-(9,9'spirobifluorene-2,2',7,7'-tetrayl)tetrabenzoic acid $\left(\boldsymbol{H}_{4} \mathbf{L} 2\right)$}

1 (0.95 mmol, $600 \mathrm{mg}), 3$-(methoxycarbonyl)phenylboronic acid (4.75 mmol, $855 \mathrm{mg}$ ) and potassium carbonate $(3.25 \mathrm{mmol}, 450 \mathrm{mg})$ were added to a mixture of toluene and deionized water $(70 \mathrm{~mL} / 15 \mathrm{~mL})$. The resulting mixture was degassed, stirred under an Ar atmosphere and heated at $80{ }^{\circ} \mathrm{C}$. While stirring at $80^{\circ} \mathrm{C}$, under argon stream, tri-tert-butylphosphine $(0.26$ mmol, $63 \mu \mathrm{L})\left(\mathrm{P}(\mathrm{t}-\mathrm{Bu})_{3}\right)$ and tris(dibenzylideneacetone)dipalladium $(0.2 \mathrm{mmol}, 180 \mathrm{mg})$ $\left(\mathrm{Pd}_{2}(\mathrm{dba})_{3}, \mathrm{CH}_{2} \mathrm{Cl}_{2}\right)$ were carefully added. The Schlenk tube was sealed and the resulting mixture was stirred at $80^{\circ} \mathrm{C}$ under an Ar atmosphere for $20 \mathrm{~h}$. After the mixture was cooled to room temperature, a saturated aqueous solution of ammonium chloride $(50 \mathrm{~mL})$ was added and the resulting mixture was extracted with dichloromethane $(3 \times 80 \mathrm{~mL})$. The combined 
extracts were dried on magnesium sulfate, and the solvent removed in vacuo. Purification by column chromatography on silica eluting with light petroleum/ethyl acetate (7:3) gave tetramethyl 3,3',3',,3','-(9,9'spirobifluorene-2,2',7,7'-tetrayl)tetrabenzoate (2) as a colourless solid (480 mg, $56 \%$ yield).

Sodium hydroxide (40 mmol, $1.6 \mathrm{~g}$ ) was added to a suspension of $2(0.56 \mathrm{mmol}, 480 \mathrm{mg})$ in ethanol and deionized water $(100 \mathrm{~mL} / 15 \mathrm{~mL})$. The resulting mixture was stirred at reflux for $12 \mathrm{~h}$. After it was cooled to room temperature, ethanol was removed under vacuo. The resulting aqueous solution was diluted with deionized water, acidified to $\mathrm{pH}=2$ using concentrated hydrochloric acid, and extracted with ethyl acetate $(3 \times 80 \mathrm{~mL})$. The combined organic layers were dried on magnesium sulfate, the solvent removed under vacuo to afford $\mathbf{H}_{4} \mathbf{L} 2$ as a colorless solid (440 mg, $99 \%$ yield). M.p. > 300 ${ }^{\circ}$; ${ }^{1} \mathrm{H}$ NMR (300 MHz, DMSO$\left.\mathrm{d}_{6}\right): \delta=12.89$ (sbr, 4H, COOH); $8.32(\mathrm{~d}, \mathrm{~J}=8 \mathrm{~Hz}, 4 \mathrm{H}, \operatorname{ArH}) ; 8.02$ (s, 4H, ArH), 7.91 (m, 8H, ArH); $7.81(\mathrm{~d}, \mathrm{~J}=8.2 \mathrm{~Hz}, 4 \mathrm{H}, \operatorname{ArH}) ; 7.51(\mathrm{t}, \mathrm{J}=8.2 \mathrm{~Hz}, 4 \mathrm{H}, \operatorname{ArH}) ; 7.06(\mathrm{~s}, 4 \mathrm{H}, \operatorname{ArH})$; ${ }^{13} \mathrm{C}$ NMR: $\left(75 \mathrm{MHz}, \mathrm{DMSO}-\mathrm{d}_{6}\right) \delta=168,02$ (C) ; 150,31 (C) ; 141,66(C) ; 140,72(C) ; 140,21 (C) ; 132,27 (C) ; 132,07 (CH) ; 130,27 (CH) ; 129,24 (CH) ; 128,26 (CH) ; 127,94 (CH) ; 122,82 (CH) ; 122,21 (CH) ; 66,75 ( $\left.\mathrm{C}_{\text {Spiro }}\right)$; IR (v): $1693(\mathrm{C}=\mathrm{O})$; 1604, 1405 ; $1311(\mathrm{C}-\mathrm{O})$; $1257 ; 1168 ; 1120 ; 1083 ; 1049 ; 1004 ; 890 ; 814 ; 758 ; 717 \mathrm{~cm}^{-1}$; UV-Vis (THF): $\lambda_{\max }=$ 316, $334 \mathrm{~nm}$; HRMS (ESI', $\mathrm{MeOH} / \mathrm{CH}_{2} \mathrm{Cl}_{2}$ 95:5): $\mathrm{m} / z$ calcd for $\mathrm{C}_{53} \mathrm{H}_{31} \mathrm{O}_{8}$ : 795.2024 [M-H']; found 795.2023 .

\section{2,2', 7,7'-tetrayltetrabenzoic acid 9,9'spirobifluorene $\left(\boldsymbol{H}_{\mathbf{4}} \mathbf{L} \mathbf{3}\right)$}

To a degassed solution of 1 (300 mg, $0.475 \mathrm{mmol})$ in anhydrous DMF (15 mL) was added copper cyanide under an argon atmosphere $(425 \mathrm{mg}, 4.75 \mathrm{mmol})$. The resulting mixture was degassed and stirred at reflux under an argon atmosphere for four days. The reaction was monitored by TLC (eluant: petrol/ethyl acetate: 4/1). After cooling to room temperature, a solution of iron III chloride hexahydrate $(6.8 \mathrm{~g}, 25.2 \mathrm{mmol})$ in a mixture of water/ethanol (4.5 $\mathrm{mL} / 4.5 \mathrm{~mL}$ ) was added. The resulting mixture is heated at reflux for $10 \mathrm{~min}$, cooled down to room temperature then carefully added to dilute $\mathrm{HCl}(37 \mathrm{~mL}, 1 \%)$ at $0^{\circ} \mathrm{C}$. The mixture was then extracted with dichloromethane and the combined organic layers were washed with an aqueous saturated solution of ethylenediaminetetraacetic acid tetrasodium salt and dried $\left(\mathrm{MgSO}_{4}\right)$. The solvent was removed in vacuo and the crude mixture was taken up with dichloromethane and filtered on silica eluting with a mixture of petrol/ethyl acetate (4/1). The crude mixture was suspended in ethylene glycol $(10 \mathrm{~mL})$ in the presence of potassium hydroxide $(0.6 \mathrm{~g}, 10.7 \mathrm{mmol})$ and the resulting mixture was heated at $200^{\circ} \mathrm{C}$ for $12 \mathrm{~h}$. After 
cooling to room temperature, water was added and concentrated $\mathrm{HCl}$ was added until $\mathrm{pH}=1$. After filtration and drying (oven at $80^{\circ} \mathrm{C}-48 \mathrm{H}$ ), the title compound was obtained as a colourless solid (yield $=68 \%$ ). The spectroscopic analyses and purity are in perfect accordance with reported data. ${ }^{7}$

\section{Syntheses of coordination polymers Zn-SBF1-4}

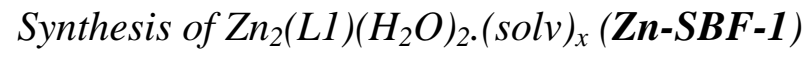

$\mathbf{H}_{4} \mathbf{L 1}\left(1.25 \times 10^{-2} \mathrm{mmol}, 10.0 \mathrm{mg}\right)$ was dissolved in a solution of $\mathrm{ZnCl}_{2}$ in $\mathrm{N}, \mathrm{N}$ diethylformamide (DEF) $(2.5 \mathrm{~mL}, 0.02 \mathrm{M})$. Ethanol $(2.5 \mathrm{~mL})$ and hydrochloric acid aqueous solution $(1 \mathrm{~mL}, 0.05 \mathrm{M})$ were added to the resulting solution, which was placed in a tightly capped PFA (perfluoroalkoxy copolymer resin) flask in an oven at $80{ }^{\circ} \mathrm{C}$ for $96 \mathrm{~h}$. Long rodlike colorless crystals were collected by filtration, washed ethanol, and dried in air.

Synthesis of $\mathrm{Zn}_{2}(\mathrm{~L} 3)(\mathrm{DEF})_{2}(\text { solv })_{x}(\mathrm{Zn}-\mathrm{SBF}-2)$ and $\mathrm{Zn}_{2}(\mathrm{~L} 3)\left(\mathrm{H}_{2} \mathrm{O}\right)_{2} \cdot(\text { solv })_{x}(\mathrm{Zn}-\mathbf{S B F}-3)$

$\mathbf{H}_{4} \mathbf{L 3}\left(1.30 \times 10^{-2} \mathrm{mmol}, 16.0 \mathrm{mg}\right)$ was dissolved in a solution of $\mathrm{ZnCl}_{2}$ in DEF (2.5 mL, 0.02 M). Ethanol (2.5 mL) and hydrofluoric acid aqueous solution ( $1 \mathrm{~mL}, 0.1 \mathrm{M})$ were added to the resulting solution, which was placed in a Teflon-lined $23 \mathrm{~mL}$ autoclave in an oven at $100{ }^{\circ} \mathrm{C}$ for $60 \mathrm{~h}$, then cooled down to room temperature at a rate of $0.1{ }^{\circ} \mathrm{C} \cdot \mathrm{h}^{-1} .2$ and 3 crystallize together and attempts to separate them in large quantities were unsuccessful due to close densities. Plate-like colorless crystals of $\mathbf{2}$ and rod-like colorless crystals of $\mathbf{3}$ suitable for single crystal X-Ray diffraction were collected and quickly drown into Paratone oil.

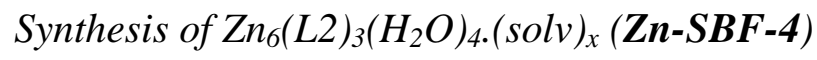

$\mathbf{H}_{4} \mathbf{L 2}\left(2.5 \times 10^{-2} \mathrm{mmol}, 20.0 \mathrm{mg}\right)$ was dissolved in a solution of $\mathrm{ZnCl}_{2}$ in DMF (2.5 mL, 0.01 M). Ethanol (2.5 mL) and hydrochloric acid aqueous solution ( $1 \mathrm{~mL}, 0.05 \mathrm{M})$ were added to the resulting solution, which was placed in a tightly capped PFA flask in an oven at $80{ }^{\circ} \mathrm{C}$ for five days. Large colorless crystals (highest size greater than $1 \mathrm{~mm}$ ) were collected by filtration, washed with DMF and ethanol, and dried in air.

\section{Single-crystal data collections and structure determinations}

Suitable single-crystals of Zn-SBF-1-4 were mounted on a four-circle APEX II Bruker-AXS diffractometer (Centre de Diffractométrie X, UMR CNRS 6226, Rennes), using Mo Ka radiation $(\lambda=0.71073 \AA)$. Intensities were collected at $150 \mathrm{~K}$ by means of the program 
Bruker SMART included in the APEX2 programs suite. ${ }^{16}$ The scaling of the integrated intensities of equivalent reflections was performed with the program SADABS. ${ }^{17}$ Reflection indexing, Lorentz-polarization correction, peak integration and background determination were carried out with the program SAINT. ${ }^{18}$ Unit-cell parameters refinement and frame scaling were performed with the program SADABS. ${ }^{17}$ Numerical absorption corrections were performed using a multi-scan absorption correction. ${ }^{19}$

Structures of Zn-SBF-1-4 have been determined using direct methods with the program SIR97 ${ }^{20}$ and models have been completed by Fourier difference calculations and refined with SHELXL-2018. ${ }^{21}$ For Zn-SBFs 1, 3 and 4, atomic positions of hydrogen atoms linked to $\mathrm{sp}^{2}$ $\mathrm{C}$ of ligands, as well as hydrogen atoms from DEF solvent in $\mathbf{2}$, have been calculated with HFIX command of SHELXL-2018. Restrains on distances and angles in DEF molecule in 2 have also been introduced with DFIX command of SHELXL-2018. For Zn-SBFs 1-3, the solvent molecules contributions have been removed by using the PLATON Squeeze routine. ${ }^{22}$

Crystallographic data and details on data collection are listed in Table 1. Structure drawings were carried out with Diamond 3, supplied by Crystal Impact. ${ }^{23}$ The pore sizes values were estimated by considering the largest sphere that can fit in the voids taking into account the van der Waals radius of the atoms of the various frameworks.

\section{Results and Discussion}

Synthesis of $\mathbf{H}_{\mathbf{4}} \mathbf{L} \mathbf{1}, \mathbf{H}_{\mathbf{4}} \mathbf{L} \mathbf{2}$ and $\mathbf{H}_{\mathbf{4}} \mathbf{L} 3$ 


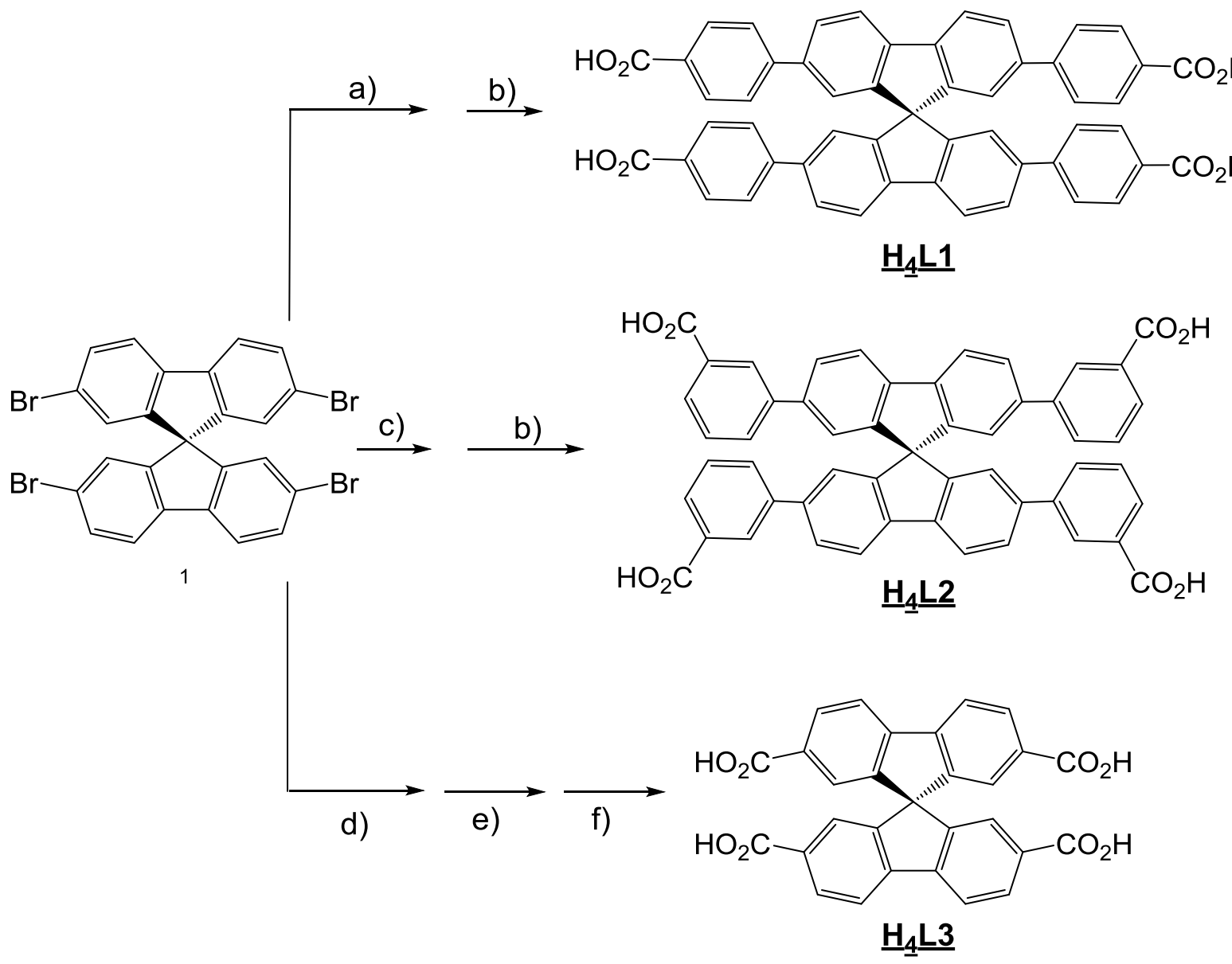

Scheme 1. Synthesis of $\mathbf{H}_{\mathbf{4}} \mathrm{L1}, \mathrm{H}_{\mathbf{4}} \mathrm{L} 2$ and $\mathrm{H}_{\mathbf{4}} \mathrm{L3}$. Reagents and conditions: a) 4-(methoxycarbonyl)phenylboronic

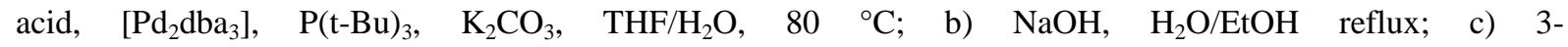
(methoxycarbonyl)phenylboronic acid, $\left[\mathrm{Pd}_{2} \mathrm{dba}_{3}\right], \mathrm{P}(\mathrm{t}-\mathrm{Bu})_{3}, \mathrm{~K}_{2} \mathrm{CO}_{3}, \mathrm{THF} / \mathrm{H}_{2} \mathrm{O}, 80{ }^{\circ} \mathrm{C}$; d) $\mathrm{CuCN}, \mathrm{DMF}$, reflux, 4 days; e) $\mathrm{KOH}$, ethylene glycol, $200^{\circ} \mathrm{C}$; f) $\mathrm{HCl}, \mathrm{H}_{2} \mathrm{O}$.

The synthesis of the target spirobifluorene-based ligands $H_{4} L \mathbf{L 1}, H_{4} L 2$ and $H_{4} L 3$ is presented in Scheme 1. The synthetic approach uses a common intermediate, i.e. 2,2',7,7'-tetrabromo spirobifluorene $\mathbf{1}$, in order to easily obtain various ligands with different geometries. Compound 1 was then first synthesized, as we previously reported through an efficient catalyst free tetrabromination of 9,9'-spirobifluorene. ${ }^{15}$ Introduction of the four aryl arms has been further achieved through Suzuki-Miyaura cross coupling reaction with either 4- or 3(methoxycarbonyl)phenylboronic acid using $\mathrm{Pd}_{2}(\mathrm{dba})_{3}, \mathrm{CH}_{2} \mathrm{Cl}_{2} / \mathrm{P}\left({ }^{\mathrm{t}} \mathrm{Bu}\right)_{3}{ }^{24}$ as catalytic system, sodium carbonate as the base in a mixture of THF and water (3/1) leading to their corresponding esters with moderate yields around $56 \%$ (it should be noted that the poor reactivity of 1 in Suzuki-Miayura cross coupling reactions has been pointed out in literature ${ }^{15,25}$ ). Finally, hydrolysis of the methyl carboxylate groups easily leads to the tetracarboxylic acid $\mathbf{H}_{4} \mathrm{~L} \mathbf{1}$ and $\mathbf{H}_{4} \mathrm{~L} 2$ with a quantitative yield. 
The synthesis of the target ligand $\mathbf{H}_{\mathbf{4}} \mathbf{L} \mathbf{3}$, with the four carboxylic acids directly connected to the spirobifluorenyl core has been previously reported by Clews and co-workers, involving a key carboxymethylation step of 2,2',7,7'-tetraiodo spirobifluorene derivative (48\% over two steps). ${ }^{7}$ In our case, the synthesis of $\mathbf{H}_{\mathbf{4}} \mathbf{L} \mathbf{3}$ has been carried through a different synthetic approach starting from the tetrabromo analogue 1 (Scheme 1). The Rosenmund-von Braun cyanation of $\mathbf{1}$ in the presence of an excess of copper(I) cyanide at the reflux of DMF leads to the expected tetracyanide derivative along with a mixture of products incorporating nitriles and amide functions. Hydrolysis of this mixture $\left(\mathrm{KOH}\right.$, ethylene glycol, $\left.200^{\circ} \mathrm{C}\right)$ cleanly leads the target ligand $\mathbf{H}_{4} \mathbf{L 3}$ with an overall yield of $68 \%$.

Therefore, we have developed efficient routes towards SBF-based ligands possessing different geometric profiles. This synthetic approach involving a common intermediate is simple and adaptable to the synthesis of various tetracarboxylate SBF-based ligands of interest for the elaboration of CPs.

\section{Crystal structures and properties of Zn-SBFs}

Table 1. Crystallographic data and structure refinement parameters for Zn-SBF1-4.

\begin{tabular}{|c|c|c|c|c|}
\hline & Zn-SBF-1 & Zn-SBF-2 & Zn-SBF-3 & Zn-SBF-4 \\
\hline Empirical formula & $\mathrm{C}_{26.5} \mathrm{H}_{14} \mathrm{O}_{5} \mathrm{Zn}$ & $\mathrm{C}_{39} \mathrm{H}_{34} \mathrm{~N}_{2} \mathrm{O}_{10} \mathrm{Zn}_{2}$ & $\mathrm{C}_{29} \mathrm{H}_{12} \mathrm{O}_{10} \mathrm{Zn}_{2}$ & $\mathrm{C}_{53.33} \mathrm{H}_{27.08} \mathrm{O}_{9.33} \mathrm{Zn}_{2}$ \\
\hline Ligand & $\mathrm{H}_{4} \mathrm{~L} 1$ & $\mathrm{H}_{4} \mathrm{~L} 3$ & $\mathrm{H}_{4} \mathrm{~L} 3$ & $\mathrm{H}_{4} \mathrm{~L} 2$ \\
\hline Molecular weight & 477.75 & 821.42 & 651.13 & 947.9 \\
\hline Crystal system & Monoclinic & Monoclinic & Triclinic & Cubic \\
\hline Space group & $P 2 / c$ & $C 2 / c$ & $P \overline{1}$ & $F d \overline{3} c$ \\
\hline Topolgy & $s q l$ & $s q l$ & $s q l$ & toc \\
\hline Z & 4 & 4 & 2 & 48 \\
\hline$a(\AA)$ & $13.360(4)$ & $18.556(1)$ & $10.750(3)$ & $44.210(2)$ \\
\hline$b(\AA)$ & $17.200(4)$ & $10.339(6)$ & $13.933(5)$ & $44.210(2)$ \\
\hline$c(\AA)$ & $14.314(4)$ & $23.224(1)$ & $14.348(5)$ & $44.210(2)$ \\
\hline$\alpha\left(^{\circ}\right)$ & 90.0 & 90.0 & $73.69(1)$ & 90.0 \\
\hline$\beta\left(^{\circ}\right)$ & $94.69(1)$ & $119.006(2)$ & $74.14(1)$ & 90.0 \\
\hline$\gamma\left(\left(^{\circ}\right)\right.$ & 90.0 & 90.0 & $68.27(1)$ & 90.0 \\
\hline$V\left(\AA^{3}\right)$ & $3278(2)$ & $3899.0(4)$ & 1881(1) & $86410(12)$ \\
\hline $\begin{array}{l}\text { Calculated density } \\
\left(\mathrm{g} . \mathrm{cm}^{-3}\right)\end{array}$ & 0.968 & 1.399 & 1.150 & 0.874 \\
\hline $\mathrm{F}(000)$ & 972 & 1688 & 652 & 23124 \\
\hline
\end{tabular}




\begin{tabular}{|c|c|c|c|c|}
\hline Crystal size $\left(\mathrm{mm}^{3}\right)$ & $0.02 \times 0.05 \times 0.18$ & $0.05 \times 0.08 \times 0.12$ & $0.03 \times 0.05 \times 0.50$ & $0.43 \times 0.71 \times 1.52$ \\
\hline Absorpt. Coeff. (mm $\left.{ }^{-1}\right)$ & 0.773 & 1.288 & 1.317 & 0.703 \\
\hline $\mathrm{T}(\mathrm{K})$ & $150(2)$ & $150(2)$ & $150(2)$ & $150(2)$ \\
\hline$\lambda(\AA)$ & 0.71073 & 0.71073 & 0.71073 & 0.71073 \\
\hline$\theta$ range $\left(^{\circ}\right)$ & $1.184-27.558$ & $2.005-27.513$ & $1.506-27.573$ & $1.303-27.482$ \\
\hline Index ranges & $\begin{array}{l}-17 \leq h \leq 17 \\
-22 \leq k \leq 20 \\
-18 \leq k \leq 18\end{array}$ & $\begin{array}{l}-24 \leq h \leq 24 \\
-13 \leq k \leq 12 \\
-30 \leq k \leq 28\end{array}$ & $\begin{array}{l}-11 \leq h \leq 14 \\
-17 \leq k \leq 18 \\
-18 \leq k \leq 17\end{array}$ & $\begin{array}{l}-45 \leq h \leq 57 \\
-56 \leq k \leq 54 \\
-57 \leq l \leq 45\end{array}$ \\
\hline Unique data & 7546 & 4482 & 8036 & 4149 \\
\hline $\begin{array}{l}\text { Observed data } \\
{[\mathrm{I}>2.0 \sigma(\mathrm{I})]}\end{array}$ & 4843 & 2829 & 3951 & 2383 \\
\hline $\begin{array}{l}\text { Number of refined } \\
\text { parameters }\end{array}$ & 295 & 221 & 371 & 147 \\
\hline Number of constrains & 0 & 19 & 0 & 0 \\
\hline $\mathrm{R}_{1}(\mathrm{I}>2 \sigma(\mathrm{I}))$ & 0.057 & 0.083 & 0.065 & 0.055 \\
\hline$\omega \mathrm{R}_{2}(\mathrm{I}>2 \sigma(\mathrm{I}))$ & 0.157 & 0.259 & 0.166 & 0.170 \\
\hline Goodness of fit & 0.95 & 1.10 & 0.86 & 1.04 \\
\hline $\begin{array}{l}\text { Largest difference map } \\
\text { peak and hole }\left(\mathrm{e} . \AA^{3}\right)\end{array}$ & $-0.66 / 0.83$ & $-1.02 / 1.20$ & $-0.86 / 0.69$ & $-0.69 / 0.40$ \\
\hline
\end{tabular}

\section{Crystal structure of $\mathrm{Zn}_{2}(\mathrm{Ll})\left(\mathrm{H}_{2} \mathrm{O}\right)_{2} \cdot(\text { solv })_{x}(\mathrm{Zn}-\mathrm{SBF}-\mathbf{1})$}

It is first important to mention that $\mathrm{Zn}_{2} \mathbf{L} \mathbf{1}\left(\mathrm{H}_{2} \mathrm{O}\right)_{2}$. (solv $)_{\mathrm{x}}$ and the previously reported $\mathrm{Cu}-\mathrm{SBF}$, $\mathrm{Cu}_{2} \mathbf{L 1}\left(\mathrm{H}_{2} \mathrm{O}\right)_{2}$. $(\mathrm{EtOH})_{4}{ }^{15}$ are isostructural, leaving aside the disordered solvent molecules. Indeed, these compounds both crystallize in the monoclinic crystal system, space-group $P 2 / c$, with very close unit-cell parameters. The asymmetric unit of Zn-SBF-1 contains one zinc atom, half a $\mathbf{L} 1$ ligand with its spiro carbon $\mathrm{C} 1$ sit on the $2 e$ Wickoff position, one oxygen

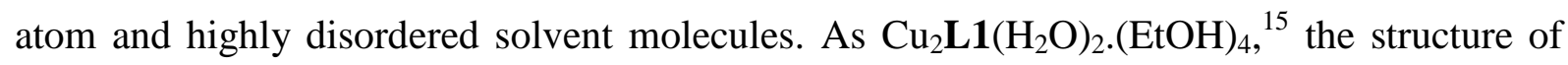
Zn-SBF-1 consists of corrugated layers with a square planar net topology (sql, point symbol $4^{4}$ ) (Fig. 1), previously reported for other paddle-wheels based CPs as the archetypal MOF-2. ${ }^{26}$ The nodes of the nets are alternatively occupied by zinc paddle-wheels, which are very common SBUs for $3 d$ metals $^{27}$, and SBF cores connected through benzoate groups of the ligands. The ligand $\mathbf{L} \mathbf{1}$ has a rigid geometry and consists in the junction via the spiro carbon of two orthogonal aryl-fluorene-aryl arms with carboxylate groups in the para position of each aryl groups ${ }^{15}$. Considering the upper and lower arms it appears that the upper arm is bent towards the bottom, while the lower arm is bent up (Fig 1), so that the four carbon atoms of the carboxylate functions are almost coplanar. Then, L1 can be considered as an organic building unit with a square planar geometry. 
Zinc atoms are surrounded by four oxygen atoms belonging to chelating bidentate carboxylate functions and one water molecule in a square-based pyramid polyhedron. The layers are piled up in a AA manner along the [001] direction, leading to monodimensional pores ( $\varnothing \approx 17 \AA$ ). The channels are filled by the disordered solvent molecules (48\% solvent accessible void as calculated by PLATON). Although the $\mathrm{O}-\mathrm{Cu}^{15}$ and $\mathrm{O}-\mathrm{Zn}$ (see SI) distances slightly differ, van der Waals interactions between the layers of Zn-SBF-1 are the same as in the structure of $\mathrm{Cu}_{2} \mathbf{L 1}\left(\mathrm{H}_{2} \mathrm{O}\right)_{2} \cdot(\mathrm{EtOH})_{4}{ }^{15}$ On one hand, apical water molecules of the paddle-wheels form hydrogen bonds with two carboxylate oxygen atoms from the adjacent layer, and on the other hand, SBF cores from neighboring layers generate $\pi$ stacking of the grids.

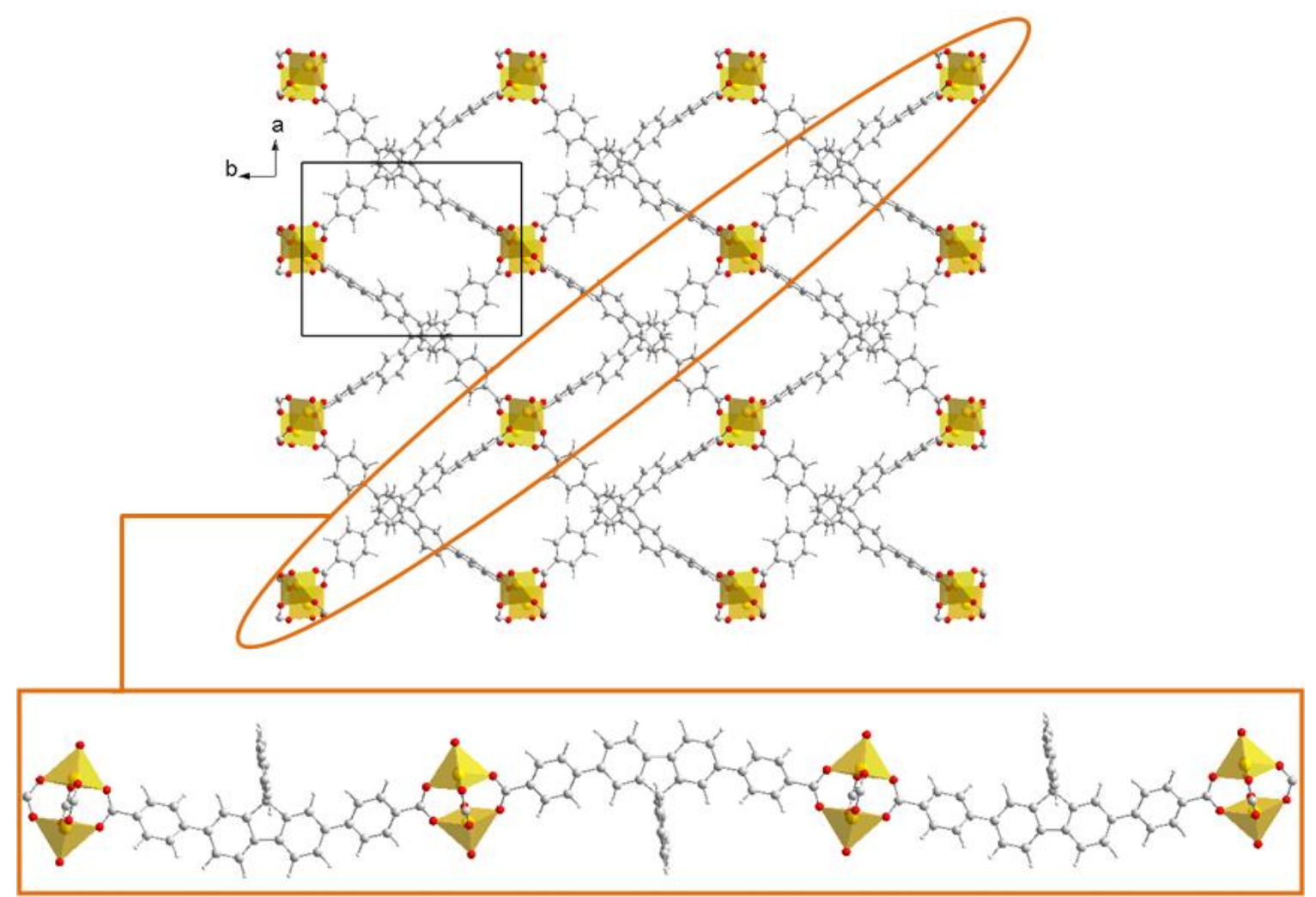

Figure 1. Crystal structure of Zn-SBF-1: projection showing channels along the [001] direction and representation of a single grid and one of its corrugated rows. Solvent molecules have been omitted for clarity

\section{Crystal structure of $\mathrm{Zn}_{2}(\mathrm{L3})(\mathrm{DEF})_{2}(\text { solv })_{x}(\mathbf{Z n - S B F - 2 )}$}

(Zn-SBF-2) is constructed with $\mathbf{H}_{\mathbf{4}} \mathbf{L 3}$ ligand, which can be seen as a shorter version of $\mathbf{H}_{4} \mathbf{L 1}$, without the phenyl units. $\mathrm{Zn}_{2}(\mathbf{L 3})(\mathrm{DEF})_{2}(\text { solv })_{\mathrm{x}}$ crystallizes in the monoclinic crystal system, space-group $C 2 / c$. The asymmetric unit contains one zinc atom, half $\mathbf{L 3}$ ligand with its spiro carbon $\mathrm{C} 1$ sit on the $4 e$ Wickoff position, and a highly disordered DEF molecule. On the 
contrary to Zn-SBF-1, the inorganic SBU in Zn-SBF-2, $\mathbf{Z n}_{2}(\mathrm{RCOO})_{4}(\mathrm{DEF})_{2}$, is not a paddlewheel but a dimer of zinc cations which are four-fold coordinated in a tetrahedral geometry. As depicted in Fig. 2, two trans equatorial carboxylate functions $\left(\mathrm{O} 1, \mathrm{O} 3, \mathrm{O}^{\mathrm{i}}, \mathrm{O} 3^{\mathrm{i}}\right)$ from two independent ligands are bridging the zinc atoms in chelating bidentate $\mu^{2}-\eta^{1}: \eta^{1}$ coordination mode, and the last two trans oxygen atoms $\left(\mathrm{O}^{\mathrm{ii}}, \mathrm{O} 5^{\mathrm{iii}}\right)$ belong to $\eta^{0}: \eta^{1}$ monodentate carboxylate functions from two other independent ligands. Two oxygen atoms from DEF molecules occupy the apical positions of the building unit.
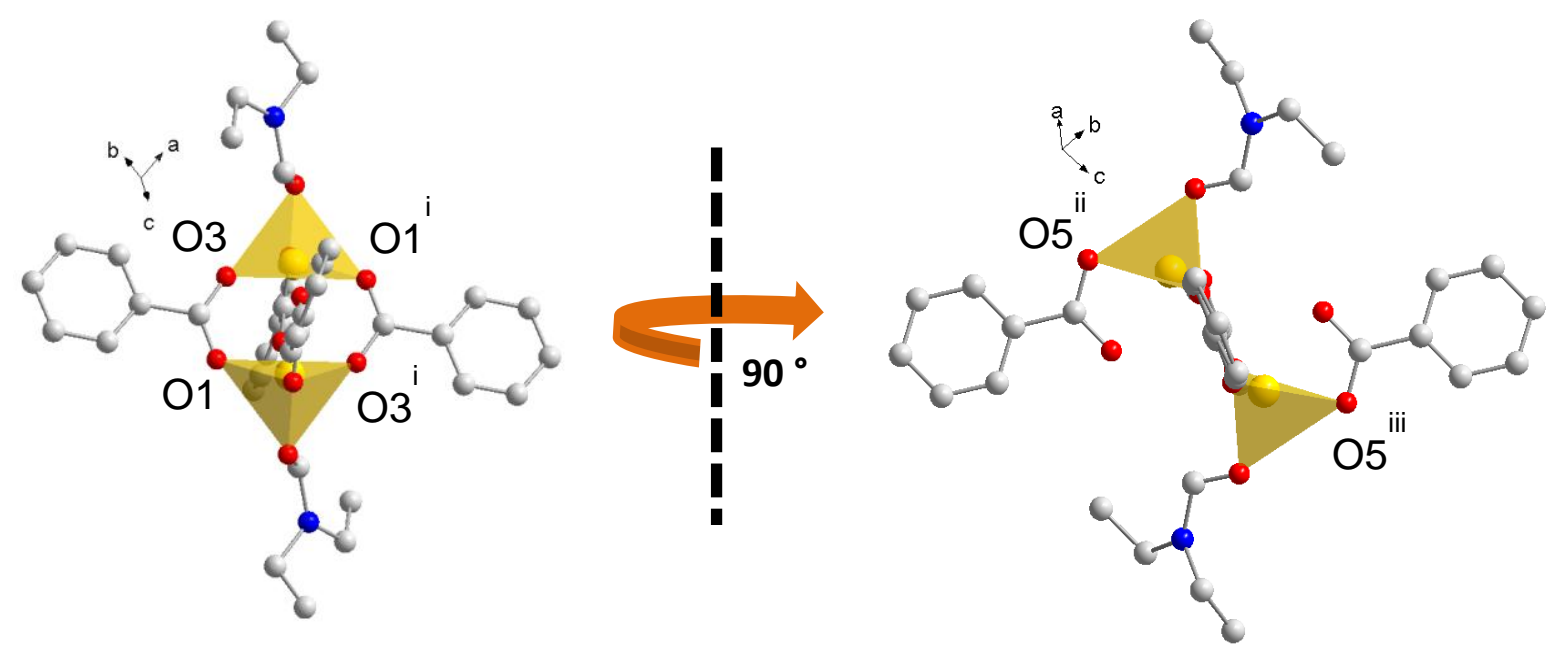

Figure 2. Inorganic SBU of Zn-SBF-2: (i) $-0,5-x$, $-0,5-y, 1-z$; (ii) $-0,5+x, 0,5-y,-0,5+z$; (iii) $x,-1+y ; 1,5-z$.

The four spiro carbon atoms from the ligands connected to the same inorganic SBU are strictly coplanar due to their position on the $c$ glide plane and they are equidistant to the centroïd of the SBU (spiro C - centroïd: 7.16 and 7.18 $\AA$ ) which is located on the 2-fold axis. Then, the inorganic unit can be considered as a square planar secondary building unit (Fig. 3) as in the case of paddle-wheel. To the best of our knowledge, this type of SBU has never been described. 


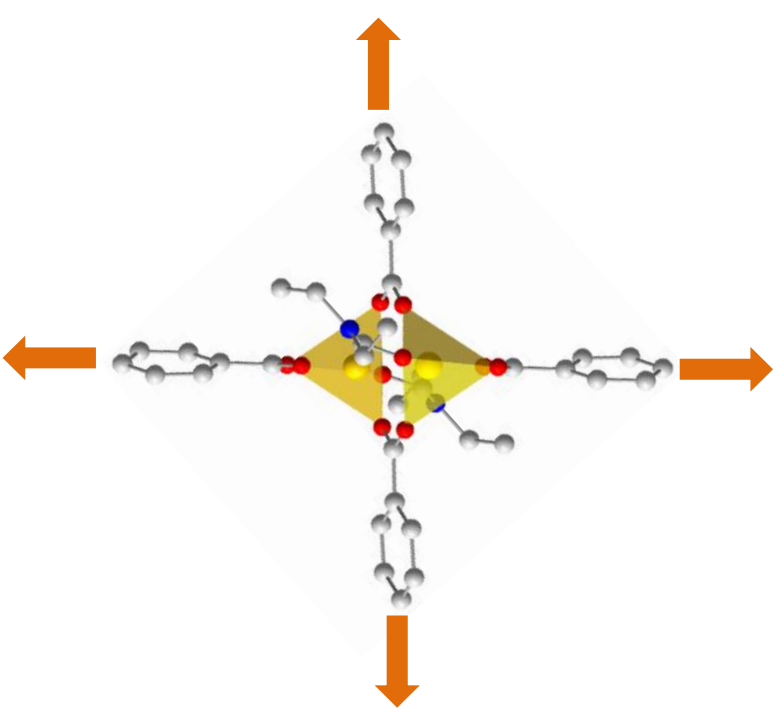

(a)

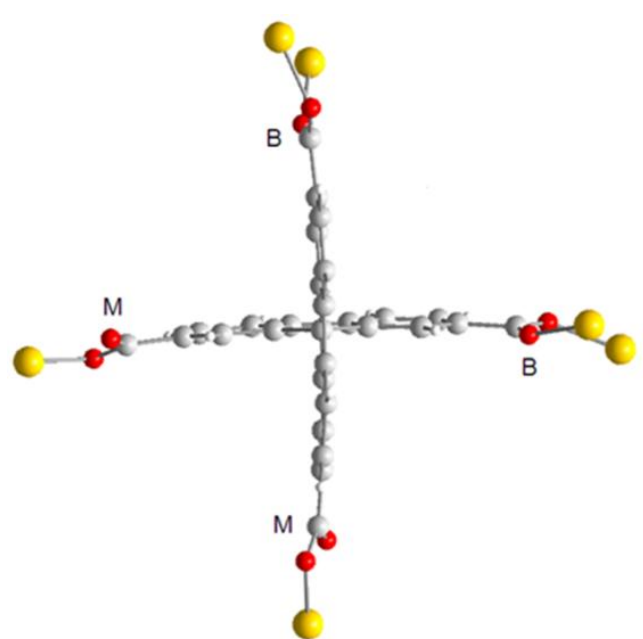

(b)

Figure 3. Representation of the square geometries of the (a) inorganic and (b) organic SBUs in Zn-SBF-2; M: monodentate; B: bidentate.

The inorganic SBUs are connected through the tetracarboxylate L3 ligands. Considering one ligand, the two monodendate carboxylate functions are in cis positions and then the two bridging functions also are in cis positions regarding the central spiro carbon atom (Fig. 3). The ligands act also as square planar building blocks since the centroïds of the four inorganic SBUs linked to each ligand are coplanar and equidistant to the spiro carbon. The resulting combination of square planar organic and inorganic SBUs leads to 2D grids with sql topology as in Zn-SBF-1 (Fig. 4).

The rows of the layers consist of inorganic SBUs connected through fluorene arms of the ligands with on one hand, alternating bidentate (B) and monodentate (M) carboxylate functions in a B-B-M-M sequence, and on the other hand, with upper (U) and lower (L) arms (Fig. 4a). Identical rows are generated by symmetry in the two directions of the layers. 


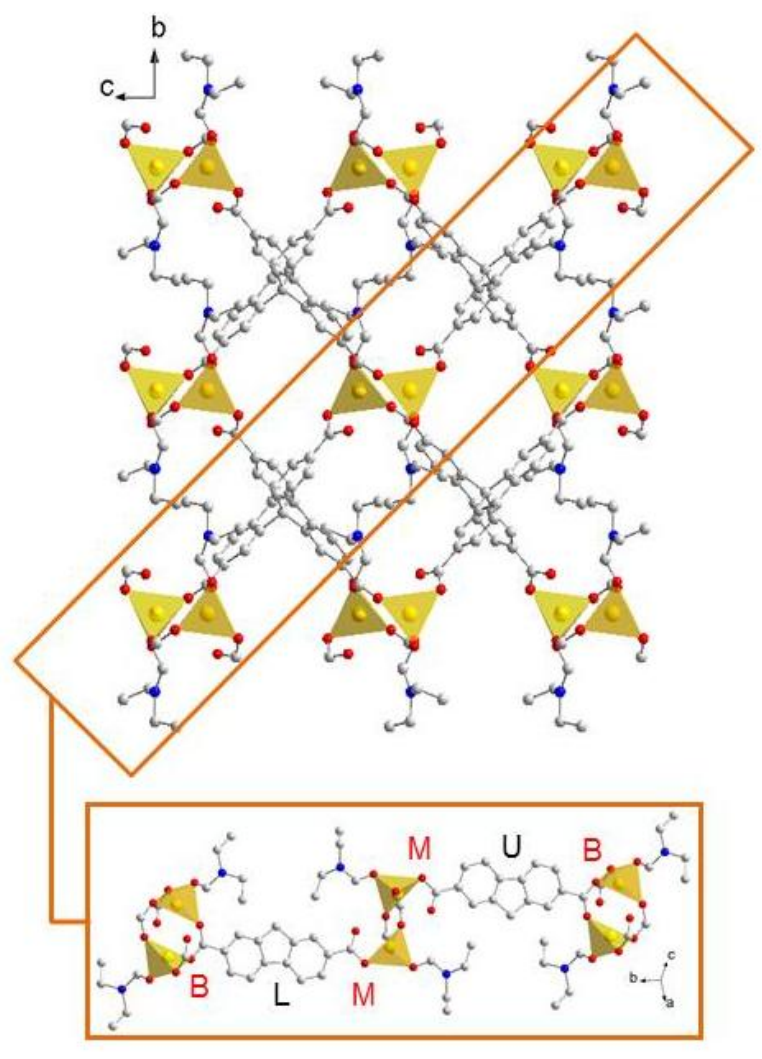

(a)

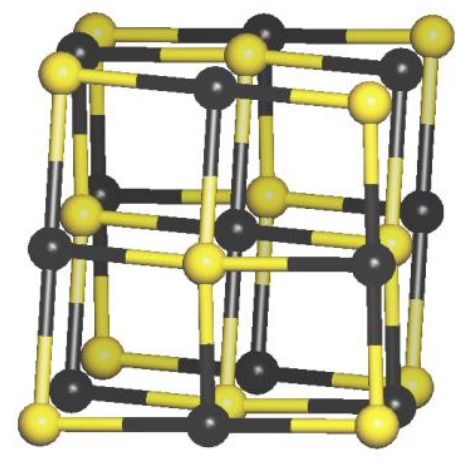

(b)

Figure 4. (a) Representation of one layer along [100] direction and one row in Zn-SBF-2 with alternating bidentate carboxylate function (B), lower arm of the ligand (L), monodentate carboxylate function (M), upper arm of the ligand (U). (b) topology of the staggered layers in a AA manner with halite-type structure in Zn-SBF-2: inorganic and organic SBUs are displayed with yellow and black nodes, respectively.

The nets are piled up in a staggered manner. Indeed, by translation along [ $\left[\begin{array}{lll}-1 & 0 & 1\end{array}\right]$ direction, inorganic SBUs replace SBF cores of the adjacent layer, and vice-versa, which generates a halite-like topological network (Fig. 4b). This stacking generates weak hydrogen bonds between the layers, involving the four hydrogen atoms from the SBF core of one ligand and the two oxygen atoms from carboxylate functions of the upper and lower inorganic SBUs (see SI). Thus, one dimensional channels are generated along the [- $\left.\begin{array}{lll}-1 & 0 & 1\end{array}\right]$ direction. These $10.35 \AA$ wide channels are largely occupied by the disordered ethyl groups of DEF molecules (see SI), which blocks the porosity of the framework. 
Crystal structure of $\mathrm{Zn}_{2}(\mathrm{L3})\left(\mathrm{H}_{2} \mathrm{O}\right)_{2} \cdot(\text { solv })_{x}(\mathrm{Zn}-\mathrm{SBF}-3)$

Interestingly, Zn-SBF-3, a CP based on the same $\mathbf{H}_{\mathbf{4}} \mathbf{L 3}$ ligand but with a slightly different crystal structure can be obtained. $\mathrm{Zn}_{2}(\mathbf{L 3})\left(\mathrm{H}_{2} \mathrm{O}\right)_{2}$. $(\mathrm{solv})_{\mathrm{x}}$ crystallizes in the triclinic crystal system, space-group $P$-1. The asymmetric unit consists of one ligand $\mathbf{L 3}$, with its spiro carbon C8 sit on the $2 i$ Wickoff position, two zinc atoms and two oxygen atoms from coordinating water molecules. Structures of Zn-SBF-2 and Zn-SBF-3 are strongly related. The inorganic building unit of Zn-SBF-3 differs from that of Zn-SBF-2 by the apical positions of the zinc dimer. Indeed, in the case of Zn-SBF-3, these positions are occupied by oxygen atoms from water molecules instead of the disordered and cumbersome DEF molecules in Zn-SBF-2. As only the apical molecules of the dimmers change, they can also be considered as square planar SBUs (Fig. 5a). In the crystal structure of Zn-SBF-3, the coordinate modes of the ligands are the same as in Zn-SBF-2, but the bridging bidentate carboxylate functions are in trans positions of the ligand (Fig. 5 b).

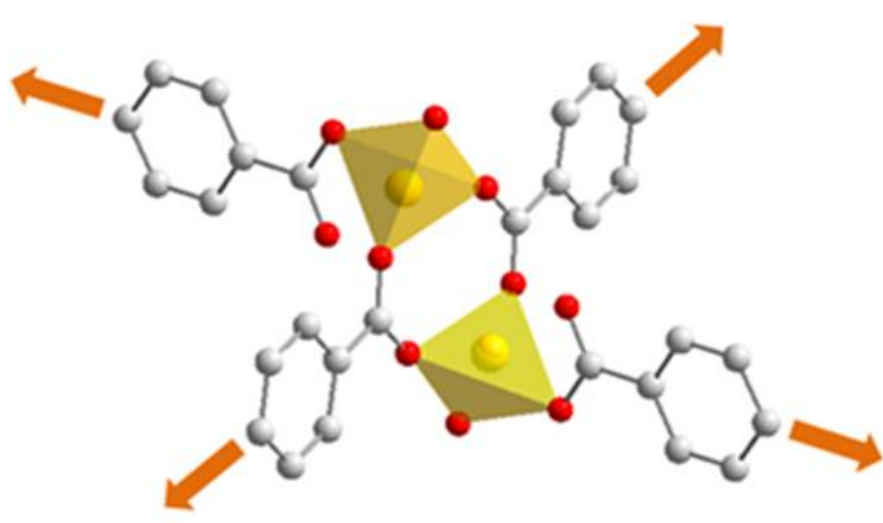

a

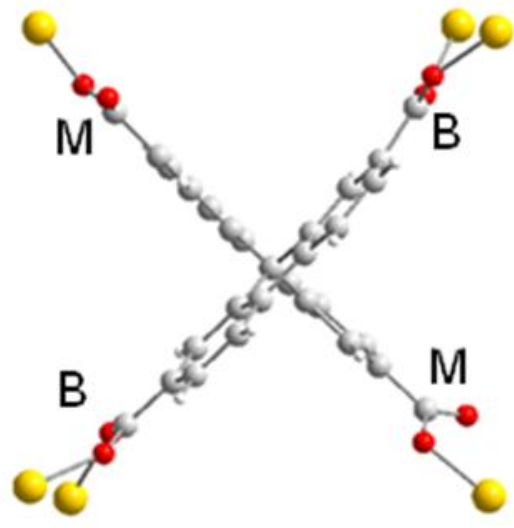

$\mathrm{b}$

Figure 5. Representation of the square geometries of the (a) inorganic and (b) organic SBUs in Zn-SBF-3; M: monodentate; B: bidentate.

In Zn-SBF-2, the symmetry of the system generates identical rows in the two directions of the grids, with alternating monodentate and bidentate coordination modes of the carboxylate functions. However, in Zn-SBF-3, the lower symmetry of the structure generates two different kinds of rows in the two directions of the grid: one with only bidentate carboxylate functions, and the other one with only monodentate carboxylate functions (Fig. 6). 


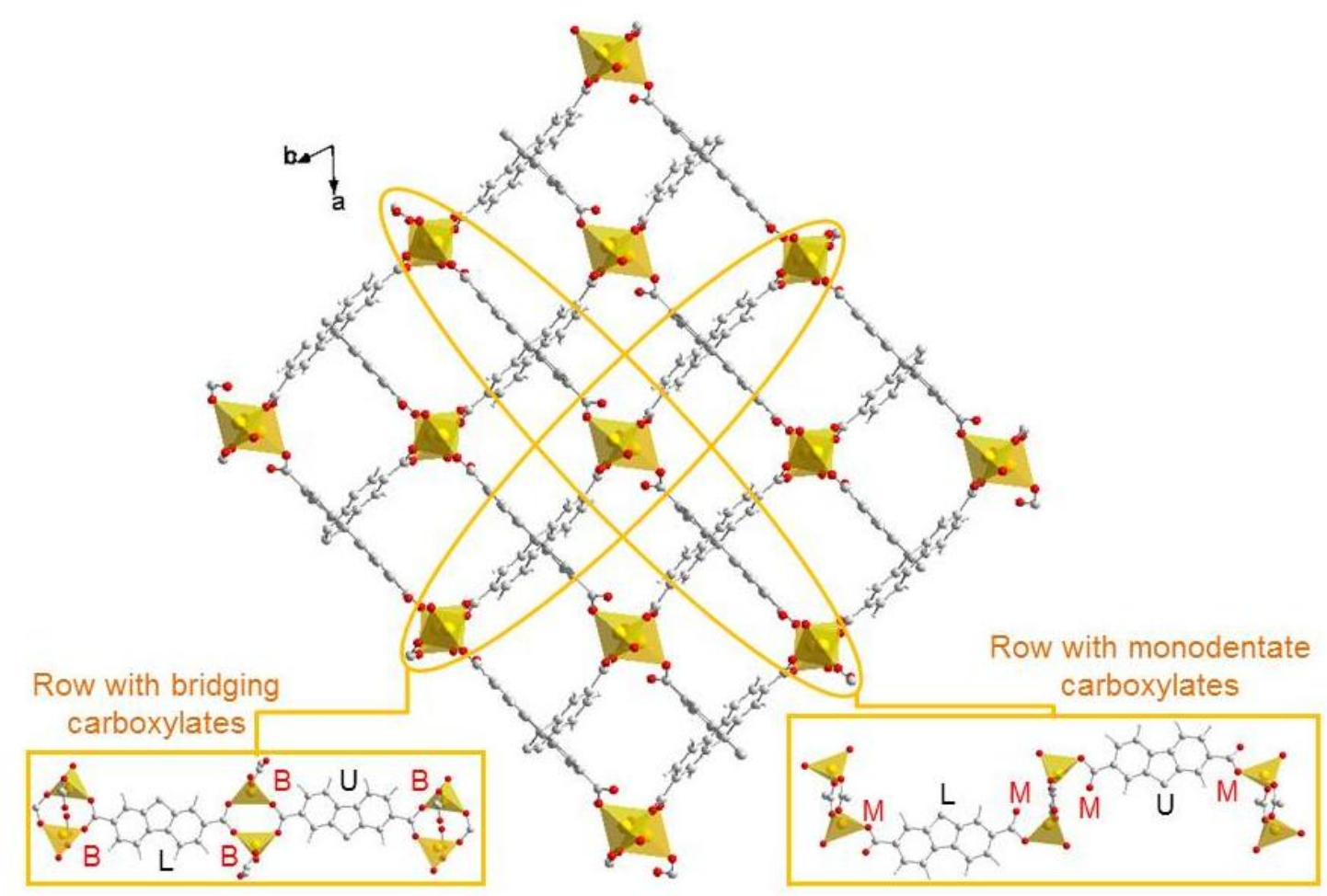

Fig. 6. (a) Representation of one layer along [001] direction and of the two kinds of rows in Zn-SBF-3, one with bidentate carboxylate function (B) alternating with lower arm of the ligand (L), and the other one with monodentate carboxylate function (M) alternating with upper arm of the ligand (U).

Another feature of $\mathbf{Z n - S B F - 3 ~ i s ~ t h a t ~ i t ~ p o s s e s s e s ~ m u c h ~ s t r o n g e r ~ i n t e r a c t i o n s ~ b e t w e e n ~ t h e ~}$ layers than Zn-SBF-2. Indeed, the apical water molecule of zinc SBUs, which is much less cumbersome than a DEF molecule, allows a greater proximity of zinc SBUs of adjacent layers, and a stacking of the nets in a $\mathrm{AB}$ manner, in such a way that SBF cores from the neighboring layers come close to each other (Fig. 7a). As a consequence the 3D cohesion of the material is held by two types of weak interactions: on one hand, the formation of hydrogen bonds between a water molecule of one SBUs and the oxygen atom from a carboxylate function of the neighboring zinc SBU (Fig. 7b) and, on the other hand, the existence of a $\pi$ stacking phenomenon between SBF cores of the ligands (Fig. 7c) (see SI). 


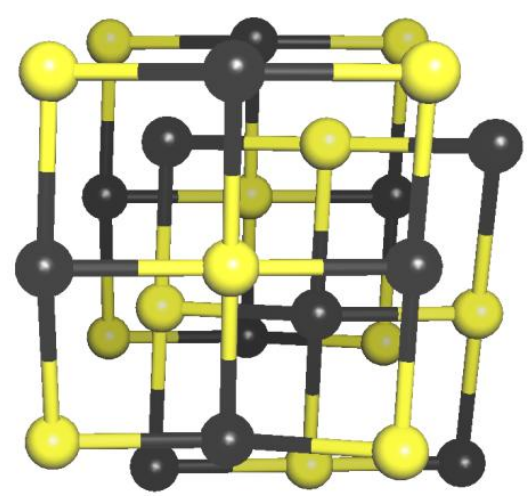

$\mathrm{a}$

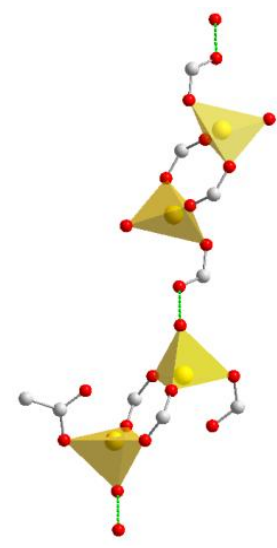

b

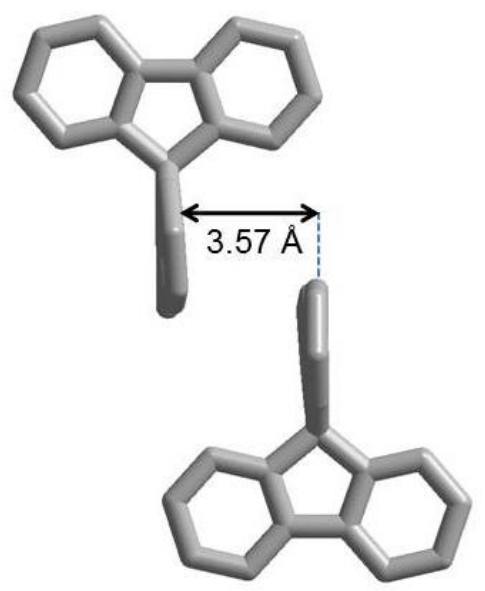

C

Figure 7. (a) Topology of the layers in a AB manner in Zn-SBF-3: inorganic and organic SBUs are displayed with yellow and black nodes, respectively; (b) hydrogen bonds in between inorganic SBUs belonging to neighboring layers; (c) $\pi-\pi$ interaction between SBF cores from neighboring layers.

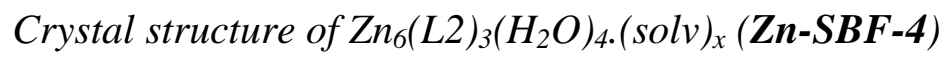

The PCP we aim to describe herein has been obtained with $\mathbf{H}_{4} \mathbf{L} 2$ ligand. $\mathbf{H}_{\mathbf{4}} \mathbf{L} 2$ is a positional isomer of $\mathbf{H}_{\mathbf{4}} \mathbf{L} \mathbf{1}$. Thus, the switching from para substituted benzoate in $\mathbf{H}_{\mathbf{4}} \mathbf{L 1}$ to meta benzoate in $\mathbf{H}_{\mathbf{4}} \mathbf{L} \mathbf{2}$ leads to a drastically different CP structure. Positional isomerism is an important concept in organic chemistry, which has drastic consequences on the electronic and structural properties of the resulting materials. ${ }^{28}$ This has been previously used in MOF chemistry ${ }^{1 \mathrm{e}, \mathrm{h}}$ but not with the SBF scaffold.

$\mathrm{Zn}_{6}(\mathbf{L 2})_{3}\left(\mathrm{H}_{2} \mathrm{O}\right)_{4}$. (solv $)_{\mathrm{x}}$ crystallizes in the cubic system, space-group $F d$ - $3 c$. Its asymmetric unit consists in one quarter of the ligand $\mathbf{L} 2$ with its spiro carbon $\mathrm{C} 1$ sit on the $48 d$ Wickoff position, two zinc cations, and an oxygen atom from a coordinating water molecule. The inorganic buildings units are octahedral secondary building units ${ }^{29}$ which consist of two tetrahedral zinc atoms with apical water molecules and a central octahedral zinc atom. Each tetrahedral zinc atom is linked to the central octahedron one by three bridging bidentate carboxylate functions from independent ligands (Fig. 8a,b). Since the benzoate groups of the ligand $\mathbf{H}_{4} \mathrm{~L} 2$ are substituted in meta position of the SBF core, the four carboxylate functions of the ligands are forming a distorted tetrahedron around the SBF core (Fig. 8c,d) and not a square plane as in $\mathbf{H}_{\mathbf{4}} \mathrm{L} \mathbf{1}$ or $\mathbf{H}_{\mathbf{4}} \mathbf{L 3}$. 


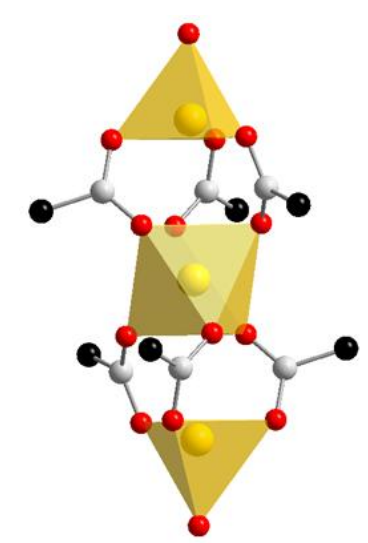

a

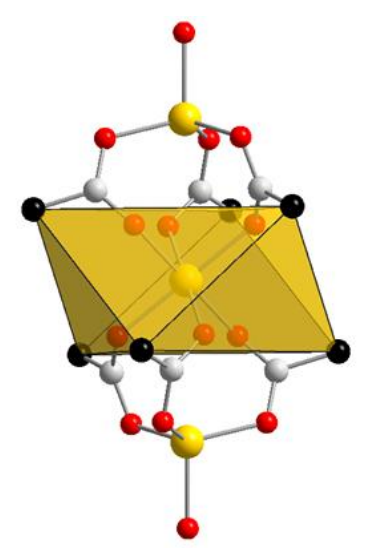

b

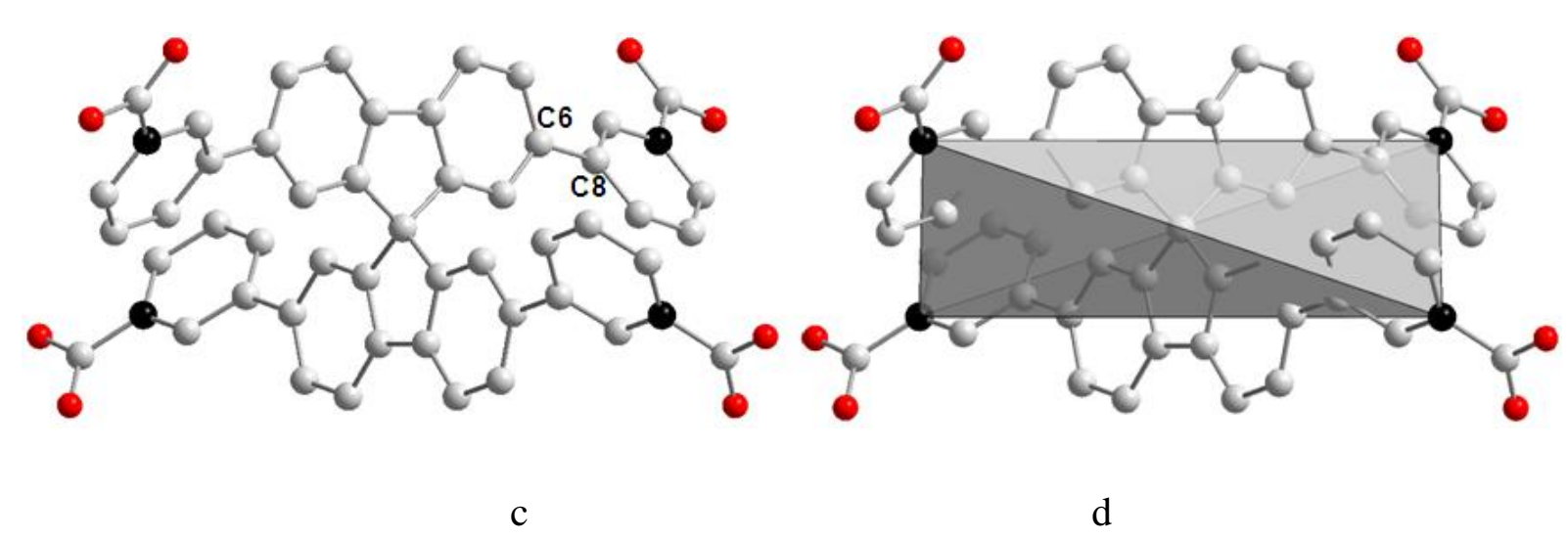

Figure 8. Representations (a) of the inorgnic SBU with Zn coordination polyhedra in ZnSBF4, (b) of the inorganic SBU with octahedral geometry, (c) of the ligand $\mathbf{L 2}$ with the meta conformation, (d) of the organic SBU with tetrahedral geometry.

The association of large tetrahedral organic building units and octahedral inorganic SBUs in a ratio 3:2 generates a three-dimensional network with a toc topology with the resulting point symbol for this binodal network $\left\{4^{4} \cdot 6^{2}\right\}_{3}\left\{4^{6} \cdot 6^{6} \cdot 8^{3}\right\}_{2}$ (Fig. 9). Zn-SBF-4 has a large potential porosity of $51 \%$ as calculated by means of PLATON with a diameter of the pores around 20 $\AA$ A. Attempts to activate the material were unfortunately unsuccessful since the treatment under vacuum triggers the collapse of the framework, presumably due to the departure of to the labile apical water molecules of the SBU. 

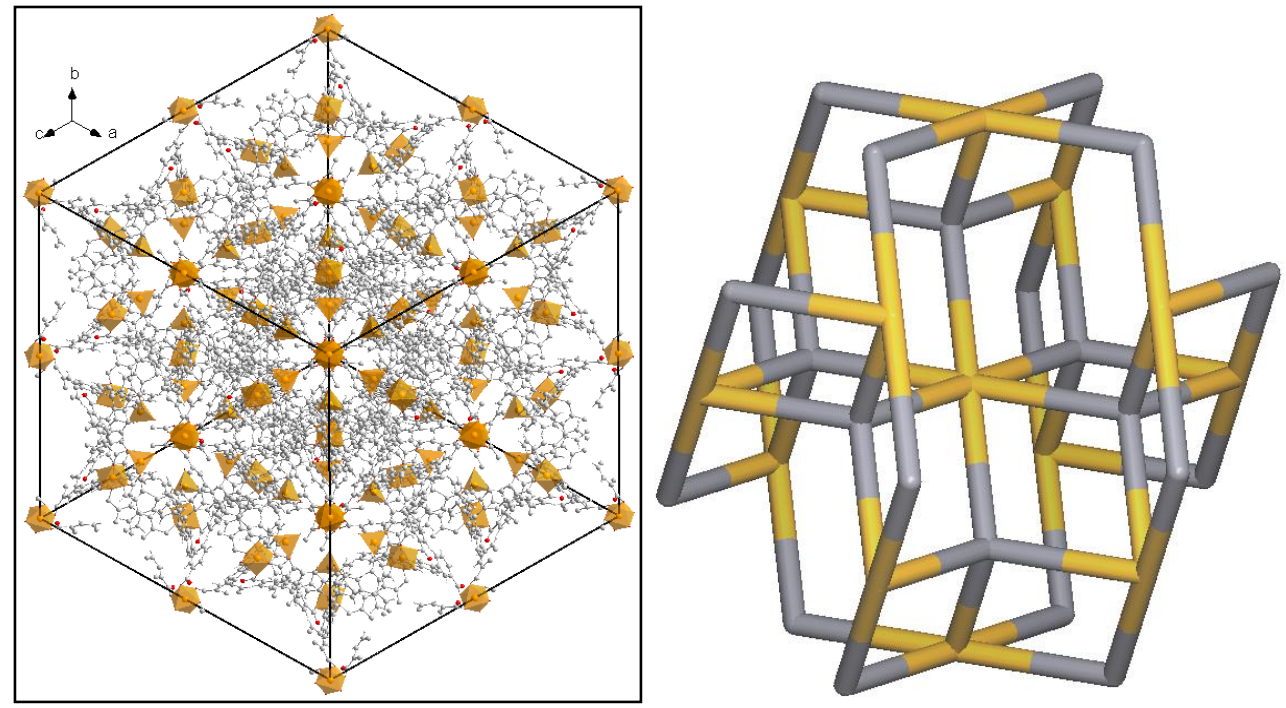

Figure 9. Representation of one unit cell of Zn-SBF-4 and of the toc topology of the net.

\section{Structural relationships}

Four new CPs have been synthesized starting from the three ligands $H_{4} L 1, H_{4} L 2$ and $H_{4} L 3$. Although they crystallize in four different space groups some structural relationships can be established. Zn-SBF-1, Zn-SBF-2 and Zn-SBF-3 possess the same $s q l$ topology. Zn-SBF-1 and $\mathrm{Cu}_{2} \mathbf{L} \mathbf{1}\left(\mathrm{H}_{2} \mathrm{O}\right)_{2 \cdot} \cdot(\mathrm{EtOH})_{4^{-}}{ }^{15}$ on one hand, and Zn-SBF-2 and Zn-SBF-3 on the other hand, are built from different inorganic building units, paddle-wheel and dimer of four-fold coordinated zinc cations, respectively, but both building units can be considered as square planar.
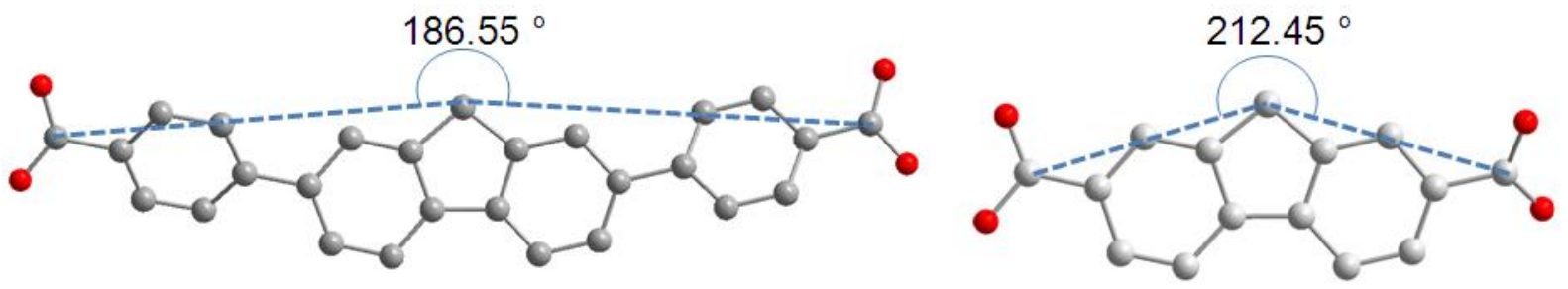

Figure 10. Structural characteristics of aryl/fluorene/aryl arms of $\mathbf{L 1}$ (left) and L3 (right) showing angles $\mathrm{C}_{\text {carboxylate }}-\mathrm{Cspiro}-\mathrm{C}_{\text {carboxylate'}}$.

In $\mathbf{H}_{4} \mathbf{L} 1$, phenyl spacers between the SBF core and carboxylate functions allow these functions to be almost coplanar. This quasi planarity of the ligand generates a $2 \mathrm{D}$ stable structure in the case of $\mathbf{Z n - S B F - 1}$ because it allows all the carboxylate functions to be bridging and thus to form paddle-wheel SBUs. On the contrary, carbon atoms from the 
carboxylate functions of $\mathbf{H}_{4} \mathbf{L 3}$ are situated more than one Angström away from the mean plane of the molecule in the structures of Zn-SBF-2 and Zn-SBF-3, compared to $0.48 \AA$ for Zn-SBF-1, which is due to the $\mathrm{C}_{\text {carboxylate }}-\mathrm{C}_{\text {spiro }}-\mathrm{C}_{\text {carboxylate }}$ angle within the ligand (Figure 10). This deviation from planarity prevents the existence of the same kind of coordination modes as in Zn-SBF-1. Indeed, in Zn-SBF-2 and Zn-SBF-3, monodentate carboxylate functions compensate the lack of planarity of the ligand, but the formed SBUs are necessarily less robust than paddle-wheels in which all carboxylate groups are bidentate. This comparison shows that the resulting inorganic SBUs depend greatly on the nature and geometry of the ligand and not only on the synthesis conditions.

The organic building units; $\mathbf{L 1}$ and $\mathbf{L 3}$, with different lengths, can still be considered on average as square planar. When associated with square-planar inorganic SBU as the paddlewheel in Zn-SBF-1, or dimers in Zn-SBF-2 and Zn-SBF-3, the resulting PCPs have 2D sql underlying nets. One can notice that Clews et al. also reported a 2D coordination polymer, in a $(4,4)$ topology, with layers stacked in $\mathrm{AB}$ manner ${ }^{7}$ which is built from ligand $\mathbf{L 3}$ with Co atoms in four-fold environment.

Only three 3D coordination polymers built from $\mathbf{L 3}$ or L1 ligands have been reported in the literature and they all involve inorganic building units different from paddle-wheels. A 3D coordination polymer built from $\mathbf{L 3}$ and tetramers of 7-fold coordinated calcium cations has been recently synthesized by Duan's group: ${ }^{13}$ the non-interpenetrating framework with a 4,8connected flu net topology and $45 \%$ of void space is built from tetranuclear oxoclusters linked by eight $\mathbf{L 3}$ ligands. Apart from $\mathrm{Cu}_{2} \mathbf{L} \mathbf{1}\left(\mathrm{H}_{2} \mathrm{O}\right)_{2}$. $(\mathrm{EtOH})_{4}{ }^{15}$ which is isostructural to $\mathbf{Z n - S B F - 1}$, two other coordination polymers based on the $\mathbf{L} \mathbf{1}$ linker have been reported. First, Park et al. reported a MOF with a 4,8-connected scu net topology, built from hexa-Zr(IV) nodes connected to eight L1. ${ }^{11}$ Secondly, the association of zinc dimers, which are not organized in a paddle-wheel in that case, connected to four ligands L1 leads to a two-fold interpenetrated 4,4-connected framework and a resulting 3D structure with the $q z d$ topology. ${ }^{12}$

In order to increase dimensionality of the framework, the use of SBUs with higher connectivity is necessary. Indeed, the framework of Zn-SBF-4, built from ligand L2 with carboxylate functions in meta position of the benzoate groups, has an underlying 3D net with 4,6 toc topology. Meta position of the carboxylate function in $\mathbf{L 2}$ allows different conformations of the ligand. As a consequence, in Zn-SBF4 the connectivity of the inorganic SBU increases to 6 when compared to a connectivity of 4 for paddle-wheels in Zn-SBF-1 or cations dimers in Zn-SBF-2 and Zn-SBF-3. This illustrates again the influence of the linker geometry, with meta versus para position of the carboxylic functions on the benzoate group, 
on the nature of the inorganic SBU. The increase of the dimensionality of the framework due to a high connectivity of the inorganic SBUs is also observed in the structures of other $\mathbf{L 1}$ or $\mathbf{L 3}$ based coordination polymers with $\mathrm{Zr}$ or Ca based 8-connected SBUs. ${ }^{11,13}$

\section{Conclusions}

We have developed efficient routes towards three SBF-based ligands possessing different sizes and geometries. This synthetic approach involving a common intermediate is simple and adaptable to the synthesis of various SBF-based ligands of interest for CPs elaboration. 2D frameworks with $s q l$ net are obtained when square planar linkers $\mathbf{L 1}$ and $\mathbf{L 3}$ are associated with paddle-wheel type SBUs, and as far as we are aware, the distorted paddle-wheel zinc dimers in Zn-SBF-2 and Zn-SBF-3 had not been previously reported. When using other inorganic SBUs with higher degrees of connectivity, 3D frameworks can also be obtained with the same $\mathbf{L 1}$ and $\mathbf{L 3}$ ligands, showing the versatility of these systems. It has also been illustrated in this work that introducing a level of conformational freedom by introducing meta-benzoate groups on spirobifluorene-based ligand L2 instead of para substituted L1 allows an increase of the connectivity of the inorganic SBUs from 4 for a paddle-wheel in $\mathbf{Z n -}$ SBF-1 to 6 for an octahedral trimer in Zn-SBF-4, leading to a non-interpenetrated 3D framework with larger void space. Therefore, it can be concluded that, for a given metal, the connectivity, and the resulting overall topology of the coordination polymers is strongly influenced by the geometry of the ligand and its interplay with the nature of the formed inorganic SBUs.

\section{Associated Content}

\section{Accession Codes}

CCDC 1939810, 1939811, 1939812, 1939833 contain the supplementary crystallographic data for this paper. These data can be obtained free of charge via www.ccdc.cam.ac.uk/data_request/cif, or by email data_request@eccdc.cam.ac.uk, or by contacting The Cambridge Crystallographic Data Centre, 12, Union Road, Cambridge CB2, 1EZ, UK; fax: +44 1223336033. 


\section{Authors' information}

\section{Corresponding Authors}

*E-mail: nathalie.audebrand@univ-rennes1.fr

*E-mail : cyril.poriel@univ-rennes1.fr

\section{Author Contributions}

The manuscript was written through contributions of all authors. All authors have given approval to the final version of the manuscript.

\section{Conflicts of interest}

There are no conflicts to declare.

\section{Acknowledgments}

Grateful thanks are expressed to Dr. T. Roisnel (Centre de Diffractométrie, UMR CNRS 6226) for his assistance in single-crystal data collection, Damien Thirion (Sciences Chimiques de Rennes UMR 6226 CNRS, Université de Rennes 1) for his fruitful advices in organic chemistry and to MENSR for financial support.

\section{References}

1 (a) Special issue on the 'Chemistry and applications of MOFs', in Coord. Chem. Rev., ed. Levason, B. and Bradshaw, D. 2015; (b) M. Schröder, Functional Metal-Organic Frameworks: Gas storage, Separation and Catalysis, Springer, 2010; (c) L.R. MacGillivray, Metal-Organic Frameworks: Design and Applications, ed. John Wiley \& Sons, Inc., 2010; (d) D. Farrusseng, in Metal-Organic Frameworks: Applications from Catalysis to Gas Storage, ed. Wiley-VCH Verlag GmbH \& Co., 2011; (e) S.R. Batten, S.M. Neville, D.R. Turner, Coordination Polymers: Design, analysis and application, ed. RSC, 2009; (f) L. Sun, M.G. Campbell and M. Dinca, Angew. Chem. Int. Ed., 2016, 55, 3566-3579; (g) X. Li, Y. Liu, J. Wang, J. Gascon, J. Li and B. Van der Bruggen, Chem. Soc. Rev., 2017, 46, 124-144; (h) S. Kaskel, The Chemistry of Metal-Organic Frameworks: Synthesis, Characterization, and Applications, Volume 1, Wiley-VCH, 2016. (i) B. Li, X.-N. Wang, A. Kirchon, J.-S. Qin, J.-D. Pang, G.-L. Zhuang, H.-C. Zhou, J. Am. Chem. Soc., 2018, 140, 14581-14585; (j) B. Li, Y.-M. Zhao, A. Kirchon, J.D. Pang, X.-Y. Yang, G.-L. Zhuang, H.-C. Zhou, J. Am. Chem. Soc., 2019, 141, 68226826. 
2 (a) L.-H. Xie, J. Liang, J. Song, C.-Y. Yin and W. Huang, Curr. Org. Chem., 2010, 18, 2169-2195; (b) R.S. Sanchez and E. Mas-Marza, Sol. Energy Mater. Sol. Cells, 2016, 158, Part 2, 189-194; (c) C. Poriel and J. Rault-Berthelot, J. Mater. Chem. C, 2017, 5, 3869-3897; (d) T.P.I. Saragi, T. Spehr, A. Siebert, T. Fuhrmann-Lieker and J. Salbeck,; Chem. Rev., 2007, 107, 1011-1065; (e) C. Poriel and J. Rault-Berthelot, J. Acc. Chem. Res., 2018, 51, 1818-1830; (f) L.J. Sicard, H.C. Li, Q. Wang, X.Y. Liu, O. Jeannin, J. Rault-Berthelot, L.S. Liao, Z.Q. Jiang and C. Poriel, Angew. Chem. Int. Ed., 2019, 58, 3848-3853.

3 F. Schlüter, K. Riehemann, N.S. Kehr, S. Quici, C.G. Daniliuc and F. Rizzo, Chem. Comm., 2018, 54, 642-645.

4 (a) C. Poriel, Y. Ferrand, P. Le Maux, J. Rault-Berthelot and G. Simonneaux, Tetrahedron Lett. 2003, 44, 1759-1761; (b) C. Poriel, Y. Ferrand, P. Le Maux, J. RaultBerthelot and G. Simonneaux, Inorg. Chem., 2004, 43, 5086-5095.

5 Y. Ferrand, C. Poriel, P. Le Maux, J. Rault-Berthelot and G. Simonneaux, Tetrahedron Asymmetry, 2005, 16, 1463-1472.

6 K.-T. Wong, Y.-L. Liao, Y.-C. Peng, C.-C., Wang, S.-Y. Lin, C.-H. Yang, S.-M. Tseng, G.-H. Lee and S.-M. Peng, Cryst. Growth Des., 2005, 5, 667-671.

7 P.K. Clews, R.E. Douthwaite, B.M. Kariuki, T. Moore and M. Taboada, Cryst. Growth Des., 2006, 6, 1991-1994.

8 C.S. Collins, D. Sun, W. Liu, J.-L. Zuo and H.-C. Zhou, J. Mol. Struct., 2008, 890, 163169.

9 L. An, H. Wang, F. Xu, X.-L. Wang and F. Wang, J. Li, Inorg. Chem., 2016, 55, 1292312929.

10 H. Li, X. Fang, S. Ma, Y. Niu, X. Zhao, J. Xu and Z. Duan, Dalton Trans., 2017, 46, 8350-8353.

11 H.J. Park, J.K. Jang, S.-Y. Kim, J.-W. Ha, D. Moon, I.-N. Kang, Y.-S. Bae, S. Kim and D.-H. Hwang, Inorg. Chem., 2017, 56, 12098-12101.

12 X. Huang, Q. Li, X. Xiao, S. Jia, Y. Li, Z. Duan, L. Bai, Z. Yuan, L. Li, Z. Lin and Y. Zhao, Inorg. Chem., 2018, 57, 6210-6213.

13 X. Fang, L. Wang, X. He, J. Xu and Z. Duan, Inorg. Chem. 2018, 57, 1689-1692.

14 L.M. Aguirre-Diaz, N. Snejko, M. Iglesias, F. Sanchez, E. Gutierrez-Puebla and M.A. Monge, Inorg. Chem., 2018, 57, 6883-6892.

15 F. Moreau, N. Audebrand, C. Poriel, V. Moizan-Baslé and J. Ouvry, J. Mater. Chem. 2011, 21, 18715-18722. 
16 Bruker-Nonius. SMART in APEX2 programs suite version 2.1-0. Bruker AXS Inc., Madison, Wisconsin, USA, 2006.

17 G. M. Sheldrick, SADABS version 2.03, Bruker AXS Inc., Madison, WI, USA, 2001.

18 Bruker-Nonius. SAINT version 7.23A. Bruker AXS Inc., Madison, Wisconsin, USA, 2005.

19 R.H. Blessing, Acta Cryst., 1995, A51, 33-38.

20 A. Altomare, M. C. Burla, M. Camalli, G. Cascarano, C. Giacovazzo, A. Guagliardi, A. G. G. Moliterni, G. Polidori and R. Spagna R., J. Appl. Crystallogr., 1999, 32, 115-119.

21 G. M. Sheldrick, SHELXL-2018: Programs for Crystal Structure Refinement, University of Göttingen, Göttingen, 2018.

22 A.L. Spek, PLATON, A Multipurpose Crystallographic Tool, Utrecht University, Utrecht, The Netherlands, 2002.

23 K. Brandenburg and M. Berndt, Diamond (version 3), Crystal Impact, Bonn, 2001.

24 D. Thirion, J. Rault-Berthelot, L. Vignau and C. Poriel, C., Org. Lett., 2011, 13, 44184421.

25 K. Sumi and G.-I. Konishi, Molecules, 2010, 15, 7582-7592.

26 H. Li, M. Eddaoudi, T.L. Groy and O.M. Yaghi, J. Am. Chem. Soc., 1998, 120, 85718572 .

27 M. Köberl, M. Cokoja, W.A. Herrmann and F.E. Kühn, Dalton Trans., 2011, 40, 68346859.

28 (a) C. Quinton, L. Sicard, O. Jeannin, N. Vanthuyne and C. Poriel, Adv. Funct. Mat., 2018, 28, 1803140-1180147; (b) J.-D. Peltier, B. Heinrich, B. Donnio, O. Jeannin, J. Rault-Berthelot and C. Poriel, Chem. Eur. J., 2017, 23, 17290-17303.

29 D.J. Tranchemontagne, J.L. Mendoza-Cortes, M. O'Keeffe and O.M. Yaghi, Chem.Soc. Rev., 2009, 38, 1257-1283. 